\title{
Retórica del negro, blanco y rojo: razonabilidad y estética para persuadir con imagenes visuales
}

$\frac{\text { José Luiz CAIVAno y Mabel A. López }}{\text { Universidad de Buenos Aires/Argentina }}$ 


\section{Resumen}

Nuestra propuesta analizará cómo el uso del color puede ser un elemento privilegiado para argumentar en una imagen visual. Los valores y connotaciones atribuidos al color en el contexto de un enunciado visual funcionan como "pruebas" en razonamientos de tipo persuasivo. De este modo, el uso de figuras retóricas no es un fin en sí mismo sino el correlato visible de la argumentación que funciona como andamiaje oculto, implícito, de la persuasión. En esta oportunidad hemos elegido el rojo, el negro y el blanco por la frecuencia de su aparición, la cantidad de usos y lo nutrido de sus interpretaciones sociocilturales -que incluso pueden resultar aparentemente paradójicas o contradictorias. Todos estos sentidos están latents" y coexisten. Los colores son reinterpretados en correspondencia con los contextos de uso en los textos mismos (co-textos), y con los efectivos contextos sociales que los enmarcan en una situación real dada (espacio y tiempo históricos).

\section{Palabras clave}

retórica, argumentación, color, textos visuales, cultura, comunicación

\section{Abstract}

Our proposal is to analyze how the use of color can be a privileged element to argue in a visual image. The values and connotations ascribed to color in the context of a visual statement work as "proofs" in reasoning of the persuasive type. In this way, the use of rhetorical figures is not an end in itself, but the visible correlate of the argumentation that works as a hidden, implicit structure of persuasion. We have chosen black, white, and red because of their high frequency in appearing, the great number of uses, and the abundance of socio-cultural interpretations --which even may be apparently paradoxical or contradictory. All these senses are latent, and coexist. Colors are reinterpreted in correspondence with the contexts of use in the texts themselves (co-text), and with the effective social contexts, which frame them in a real situation (historical space and time).

\section{Key words}

rethoric, argumentation, color, visual texts, culture, communication 


\section{Introducción}

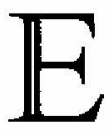

n esta propuesta veremos cómo el uso del color puede ser un elemento privilegiado para argumentar en una imagen visual. Hemos elegido el negro, el blanco y el rojo por la frecuencia de su aparición, la cantidad de usos y lo nutrido - e incluso aparentemente paradójico o contradictorio- de sus interpretaciones socioculturales.

Esta selección tiene también un argumento filogenético. El hombre primitivo veía al negro y al rojo como colores que inquietaban su reposo. A partir de la vida en la selva, el hombre se hizo predominantemente visual, su alimento y sexo estaban ligados a la luz. La negra noche y su rojo preludio, el crepúsculo, anunciaban la cercanía del peligro. Cuando el bosque se transformaba en negra espesura, el hombre, carente de visión nocturna, estaba expuesto a los predadores (más fuertes, con mejor olfato y más aguda audición). Los rojos reflejos del fuego lo fascinaban en esas extensas e inquietantes noches en las que rondaba un peligro real, tangible. Podriamos imaginarnos ese sentimiento ancestral recordando el temor que nos infundía la oscuridad cuando éramos niños. El negro y el rojo se asociaban con los peligros que acechaban la supervivencia de la especie. Son alertantes el negro de la noche, el rojo de la sangre y las fieras. Por el contrario, son tranquilizadores el blanco y azul claro del día, los marrones y verdes de la tierra y el follaje. El hombre construyó refugios, iluminó la oscuridad y dominó el mundo natural; sin embargo, su cerebro aún no ha olvidado. Discriminar el color del peligro ya no es información relevante para salvar la vida de nuestra especie, sin embargo, todavía hay resabios en la memoria primitiva del cerebro 
arcaico humano que nos hacen reaccionar ante esos estímulos (López Pasquali 1998).

Tenemos también un argumento lingüístico y antropológico. Berlin y Kay (1969) han investigado los nombres básicos de color en lenguas diversas a lo largo del mundo. Distinguen once términos básicos de color que se repiten en las más variadas culturas: blanco, negro, rojo, verde, amarillo, azul, marrón, púrpura, rosado, anaranjado y gris. Paralelamente elaboran una teoría sobre la evolución de los nombres usados para denominar los colores, que consta de siete estadíos. El primero (las culturas que tienen sólo dos nombres de color) corresponde al blanco y negro. Inmediatamente, en el estadío siguiente, la tercera categoría que emerge es el rojo. El rojo, entorices, incluye todos los rojos, anaranjados, marrones, rosas y púrpuras (Figura 1). Evidentemente, comunicar esta sensación pérceptual cromática era decisiva en las comunidades primitivas, por eso el rojo aparece nombrado a cóntinuación de los colores acromáticos, cuya distinción equivalia al valor (claro-oscuro). Con la tercera categoría no sólo aparece un nombre de color sino una nuevá dimenísión cognitiva: la categoría de color cromático. Este tercer término, "rojo", equivalía a dècir "color".

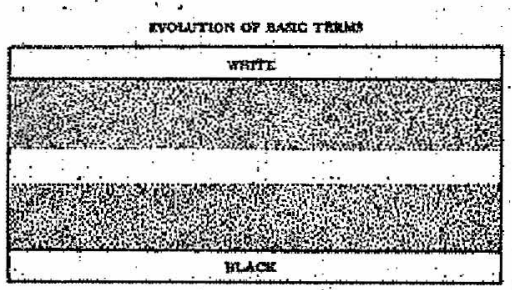

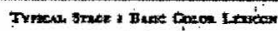

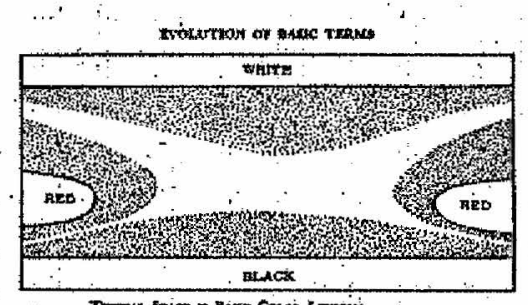

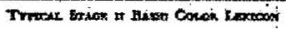

Figura 1. Estadios I y || en la evolución de los términos básicos de color (Berlin y Kay 1969).

La tríada negro-blanco-rojo aparece frecuentemente en distintas formas de decoración sobre la piel en los pueblos primitivos (Hutchings 1989). Estos colores sirven para distinguir a los personajes centrales de una ceremonia. En los cuentos tradicionales se usa la

1. En castellano, "rojo" es sinonimo de "colorado": que posee color. 
oposición negro-blanco para representar la antítesis entre el bien y el mal. El rojo simboliza la sangre de Cristo o es utilizado para asustar (Hutchings 1993).

Esta tríada es usada frecuentemente en diversos rituales para simbolizar el pasaje de un estado a otro: nacimiento, boda, bautismo, funerales (Hutchings 1997).

En Oriente, el rojo significa autoridad, poder, salud, buena suerte, ideologías políticas; se usa para purgar la maldad. Por debajo de estas ideas hay un trasfondo religioso y filosófico compartido por el mundo oriental (Kwon 2002).

Del mismo modo que en Occidente, desde la Antigüedad, se usaba una pulsera de coral como amuleto para proteger al niño de las enfermedades, en Sudamérica se mantiene la creencia de que una cinta roja en la muñeca del bebé u oculta entre sus ropas rechazará las influencias negativas (maldad, envidia, enfermedad) que él atrae por su fragilidad y belleza.

En la iconografía cristiana el negro y el rojo simbolizan el mal (el diablo, el infierno). Aunque también el rojo adquiere valores positivos. $\mathrm{Re}$ presenta la caridad, porque es la sangre derramada por Cristo para la salvación del mundo. En las imágenes de la Virgen, el azul de su manto es virginidad y el rojo, la virtud de la caridad.

El poder de la alquimia se manifestaba por el color, especialmente por el negro, blanco y rojo. En un manuscrito del 1550 aparece un diagrama que muestra Figura 2. Diagrama en un manuscrito de $\mathrm{H}$. la penúltima fase de Reusner, reproducido en Gage (1993: 147). transmutación de metales básicos en oro. El semicírculo inferior señala la progresión alquímica desde el blanco al negro pasando por el rojo (Figura 2).

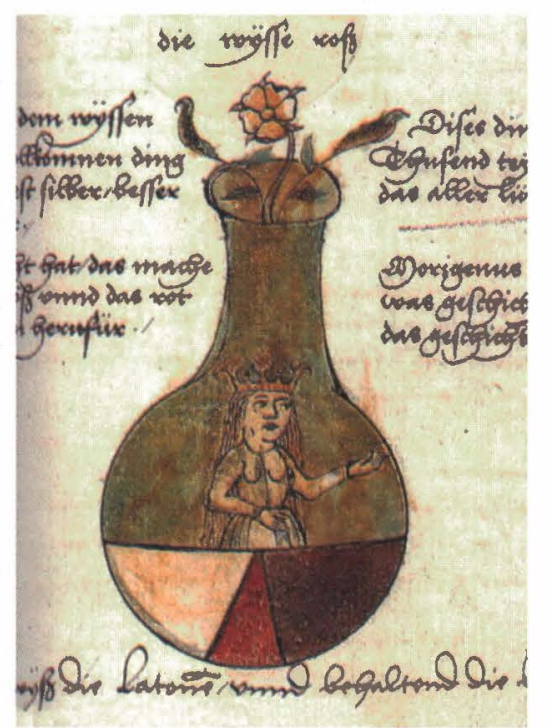


Esta tríada cromática tuvo un lugar privilegiado en la heráldica. Con argumentos muy poco rigurosos y contradictorios se establecían normativas. Por ejemplo, a fines del siglo XIV, un escritor heráldico inglés consideraba que el rojo era equidistante al negro y al blanco - aunque no explicaba por qué- y era el color más apropiado para los príncipes, pues simbolizaba la valentía. Durante el siglo XIX se desarrolló una interpretación más psicológica de la simbología del color. La "Tabla sinóptica" de Humbert de Superville, de 1827, caracteriza al rojo como violento y expansivo, al blanco como el estado de equilibrio, calma y claridad, y al negro como la convergencia, concentración y solemnidad (Gage 1993: 90).

La vida en grandes conglomerados urbanos ha modificado las condiciones materiales de la existencia humana. La indefensión ante el peligro, propia de la especie, el miedo a la noche y a la propia sangre que pudieran arrebatarle las fieras, sufren algunas metamorfosis, aunque no desaparecen del todo.

Los estímulos cromáticos —-mediatizados por la cultura- reproducen algunas de esas sensaciones más primarias. ¿Por qué o para qué lo hacen? Uno podría preguntarse: ¿qué busca el hombre al evocar los amargos terrores ancestrales? Quienes proponen mensajes persuasivos en el marcó de la cultura de masas usan de modo retórico esta combinación tricromática con el objetivo de convencer, disuadir o seducir al público.

En los nuevos entornos comunicativos y virtuales en los que el hombre se desenvuelve, el uso del color impacta en los sentidos de modo previo a cualquier reflexión sobre el mensaje. Esto representa una gran ventaja cuando la competencia y lo efímero de las comunicaciones son una constante. La persuasión retórica (en este caso por medio del color) sólo es de utilidad cuando hay más de una voz, justamente, en las comunidades en donde es posible el disenso y puede desarrollarse la multiplicidad de opiniones. Por eso, la retórica nace en el contexto democrático de la Grecia clásica, como método para imponer un argumento. 


\section{La antigua retórica}

La antigua Retórica aristotélica es la primera obra que expuso una técnica para persuadir y lograr adhesión por parte del público (Aristóteles 350 a.C.). Este camino retórico debía recorrerse en cinco etapas: inventio, dispositio, elocutio, memoria y actio. Para argumentar en favor o en contra de algo, o sobre la utilidad o inconveniencia de determinada cosa, era necesario encontrar qué decir (los argumentos apropiados) y cómo expresar esas ideas. La parte de la retórica que se ocupa de las figuras del discurso usadas para persuadir (cómo decir) se denomina elocutio. Durante mucho tiempo se generalizó y extendió el análisis de los tropos o figuras para explicar los usos estéticos y creativos del lenguaje, su función poética. Los desvíos que aparecen en los textos creativos respecto de los usos ordinarios del código se corresponden con un nutrido repertorio de figuras retóricas que los estudios de la poética fueron acuñando durante siglos.

De las cinco partes en que se organiza la retórica, sólo abordaremos dos, la inventio y la elocutio - consideradas centrales para la persuasión visual. Quien enuncia un discurso visual da su primer paso en la inventio, buscando los argumentos cromáticos, es decir, proponiendo un razonamiento pseudo-lógico en el cual el color interviene en las premisas y es portador de una conclusión. En una fase posterior, en la elocutio, el cómo decir, esos usos del color se corresponden con la utilización de tropos o figuras retóricas generadas por un uso particular, intencional, transgresor del color. Las figuras retóricas presentan un desvío conceptual o formal producido en un enunciado con el objeto de que el receptor lea una significación más allá de lo literal.

Los enunciados generados por la máquina retórica —más allá del efecto real en el público, cuyo impacto es bastante difícil de medir- promueven la reflexión, buscan el razonamiento del destinatario. El mensaje persuasivo se sustenta en una lógica, que - a diferencia de la lógica científica - no se basa en verdades 
sino en argumentos creíbles, valores y presunciones aceptadas por sus destinatarios. El dominio de la técnica retórica no es el saber científico sino la doxa, ${ }^{2}$ la opinión corriente, lo que es razonable sin que medie una demostración que le otorgue validez universal. Justamente, la doxa se caracteriza por ser un cuerpo de saberes opinable, más cerca del sentido común que de la verdad o la falsedad en el sentido lógico.

El uso retórico del negro, blanco y rojo estará basado en premisas compartidas, que cohesionan a un grupo social. Esta "ideología" es proveniente tanto de creencias acerca de la percepción humana, de asociaciones metonímicas (sangre, noche, fuego) como del orden metafórico, es decir, de la memoria cultural (luto, guerra, pureza, diablo, infierno, emblemas políticos, nacionalidades, etc.). Algunas de las creencias o asociaciones más frecuentes en la cultura occidental actual son: "Lo negro es siniestro"; "Lo negro es inquietante, misterioso"; "Lo negro deprime"; "Lo blanco es limpio, aséptico"; "El blanco es pureza"; "El blanco es neutralidad", "El rojo excita la visión, es alertante"; "La sangre (roja) es sinónimo de peligro"; "El rojo es vital, pasional"; "El rojo es alegria". Queda explicito el carácter incluso paradójico de estas afirmaciones, que adquieren valores positivos (vida, euforia) o negativos (muerte, disforia) según los contextos.

\section{Clases de razonamiento}

Una vez que se han seleccionado los argumentos más eficaces, porque generarán mayor credibilidad en el destinatario que se quiere convencer, será necesario decidir el tipo de razonamiento elegido para persuadir. La lógica argumentativa puede adoptar una forma inductiva (dando ejemplos y modelos para

2. Doxa en griego significa opinión, manera de ver, idea, parecer, creencia. Se opone al verdadero saber que los griegos llamaron episteme (inteligencia, conocimiento, saber, ciencia). Esta distinción es básica para comprender por que Platón desconfiaba de la oratoria. Mientras la ciencia tiene por objetivo alcanzar el saber, la persuasión retórica propia de la oratoria sólo busca la adhesión del público (muchas veces halagándolo demagógicamente). 
identificarse e imitar), deductiva (exponiendo un razonamiento) o abductiva (mostrando un rasgo que implica la pertenencia a un caso).

La inducción se basa en el ejemplo (exemplum) para persuadir mediante la identificación del público con el referente propuesto como modelo. Es la forma de persuasión más inmediata o primaria, que requiere menor reflexión por parte del público. Se muestra o se habla de un particular con determinadas características (para imitar o reprobar), para concluir en la identificación personal del destinatario con la figura propuesta. Es un argumento por analogía. Un tipo particular de ejemplo es la imago, una imagen conocida y representativa socialmente, capaz de encarnar los valores que se intenta promover. En este caso, el éxito del argumento dependerá enteramente de la credibilidad del personaje.

Cuando no hay una identificación primaria sino una forma más sofisticada y mediatizada de llegar a la comprensión del mensaje apelativo, seguramente habrá deducción. Para comprender esta forma de argumentar es necesario partir del silogismo, la forma más conocida de razonamiento deductivo usado como método de conocimiento científico. Más allá del terreno científico, el uso de la deducción como método persuasivo aparece en múltiples campos, como la argumentación periodística, publicitaria, politica, pedagógica, el debate parlamentario, la deliberación judicial, la prédica religiosa, la arenga militar o, simplemente, para convencer a otro de algo en la vida cotidiana. Este razonamiento, llamado entimema, se basa en la forma lógica del silogismo, pero se diferencia por el objetivo que persigue: no intenta convalidar la verdad de determinadas afirmaciones sino persuadir a un auditorio sobre los argumentos propuestos. Las premisas de las que se nutren los entimemas son sentencias que aparecen como irrefutables, aunque sean sólo presumiblemente verdaderas. Algo que parece evidente puede modificarse con el correr del tiempo. Las presunciones tienen la cualidad de ser creencias que, en alguna circunstancia, admitirian su contraria (esto prueba que no son verdades absolutas), pero tampoco son mentiras. Persuadir sería una tarea inútil o imposible si no hubiese un campo fértil, propicio para aceptar los argumentos. 
La inferencia abductiva es posterior a la lógica aristotélica; se trata de un modo inferencial, que, en rigor, carece de valor de verdad (Peirce 1860-1908: vol. 2, par. 270). Sin embargo, es muy útil. en la próducción de nuevas hipótesis en un contexto de descubrimiento. La persuasión que apela a un razonamiento abductivo propone un salto inferencial entre un rasgo.que se expone en un particular y una regla general, que subyace y es reconocible por el intérprete. La conclusión es sobre un caso en donde la posesión de un rasgo implica la pettenencia a ese universo, conjunto o fenómeno. La intuición abrevia el camino hacia la comprensión, aunque su veracidad es más frágil, dado que el razonamiento permite formular una conclusión.general a partir de una situación particular.

\section{Tres géneros persuasivos}

Veamos cómo funcionan el negro, blanco y rojo en la comunicación urbana moderina. Con el objeto de ejemplificar cómo se encarnan' los argumentos acerca de esta tríada cromática, proponemos una tipificación de las situaciones a través de un repertorio de ejemplos. En todos los casos se busca que el destinatario actúe (que haga algo o cese en una acción, que piense o compre algo). La persuasión se corporiza en géneros discursivos que regulan las características, la circulación y las funciones de los mensajes en la comuniçación urbana moderna "diseñada". Distinguimos tres modalidades en el uso de estos colores, que se corresponden con tres géneros persuasivos: señalética, propaganda y publicidad. Cada una tomará sólo algunos de los sentidos expuestos y activará una porción de las connotaciones atribuidas a estos colores.

\section{Señalética}

Rojo y negro sobre fondo blanco aseguran una excelente legibilidad y, a la vez, un importante impacto visual, argumentos perceptuales para usar esta combinación cuando se necesita asegurar 
una rápida y eficaz lectura. Las señales alertan al destinatario excitando la visión, persuaden sobre las conductas apropiadas o lícitas, inapropiadas o ilícitas en el contexto ciudadano. Las señales, además de persuadir, pretenden exponer un mensaje casi universal. Para ser útiles deben contener un alto grado de información clara y unívoca para la mayor parte del público. En la Figura 3 podemos ver señalizaciones urbanas de distintas culturas que responden a estas características. En el aspecto lógico de la persuasión (la inventio), adoptan la vía inductiva. Muestran esquemáticamente ejemplos de conductas o situaciones con las que el destinatario puede identificarse. En el nivel de la elocutio, la figura retórica dominante es la estilización. El color negro de la figura suprime rasgos, recorta sobre el fondo blanco sólo los aspectos relevantes en el reconocimiento del objeto. Ya desde los comienzos de la letra impresa se había advertido la conveniencia del uso del papel blanco, letra impresa negra y destacados en tinta roja, como una combinación que aunaba criterios de excelente legibilidad y elegancia.
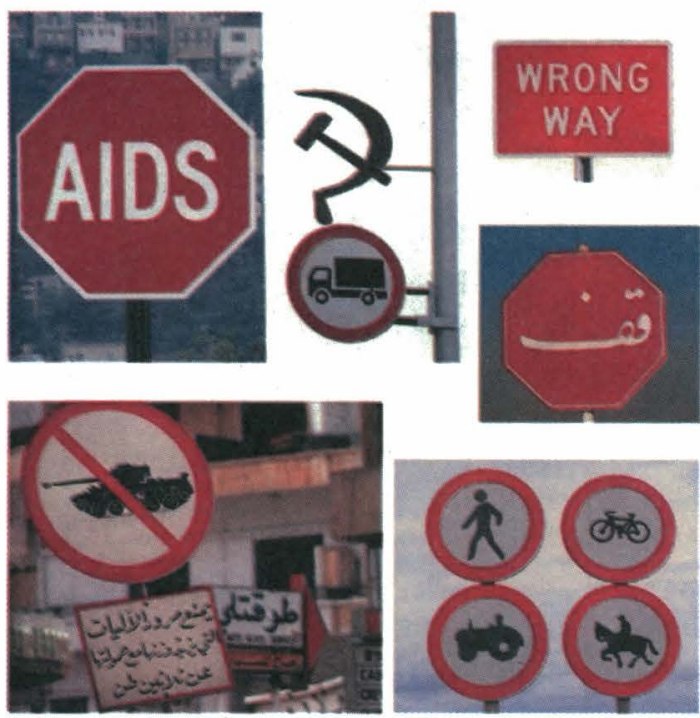

Figura 3. Señales urbanas de distintos países y culturas.

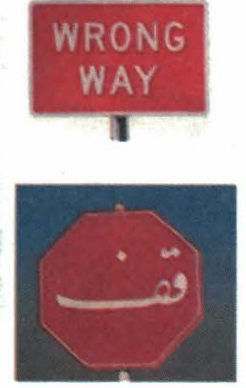




\section{Propaganda}

El segundo género está constituido por los mensajes propagandísticos, con sus verdades opinables. El uso del rojo y negro, matizados por el blanco, resulta ideal para transmitir mensajes de bien público (no publicitarios). Por ejemplo, prevención con riesgo de muerte: tabaquismo, accidentes, contaminación, violencia, mensajes antibélicos. El género de la propaganda promueve mensajes de interés social, sin un explícito móvil comercial. Esta modalidad tiene dos vertientes: la orientación social y la política.

La Figura 4 muestra un cartel antibélico de una organización comunista de Gran Bretaña, que circuló en 1920. La argumentación

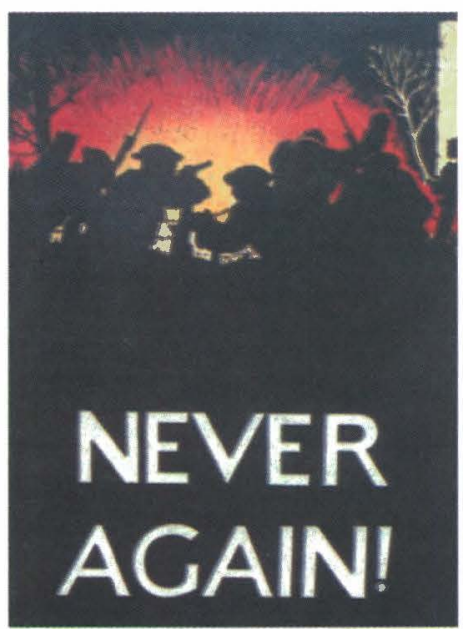

Figura 4. Afiche antibélico de 1920, Gran Bretaña. apela a una lógica inductiva (exemplum). Las escenas representadas (figuras negras sobre fondo rojo) corresponden a la Primera Guerra Mundial, la tipografía contrastante: "Never again" destaca en blanco la leyenda. El argumento recuerda el horror y la muerte del combate en el campo de batalla, para disuadir a la sociedad de una posible reincidencia (ya sabemos que no tuvo éxito). El recurso utilizado es la sinécdoque (la parte por el todo), ya que se muestra parcialmente un suceso para representar un todo, la guerra. Los colores operan de un modo metonímico, muestran la causa para significar el efecto. Las figuras ensombrecidas representan la muerte. El rojo del fuego de la batalla es la sangre derramada de los combatientes. La tipografía blanca representa la neutralidad, la construcción de un futuro claro y tranquilizador, que se opone de modo antitético al tenebroso pasado reciente.

En el ejemplo de la Figura 5, que pertenece a una campaña de prevención de accidentes de tránsito en la ciudad de Miami, la argumentación no es simplemente la exposición de un ejemplo 


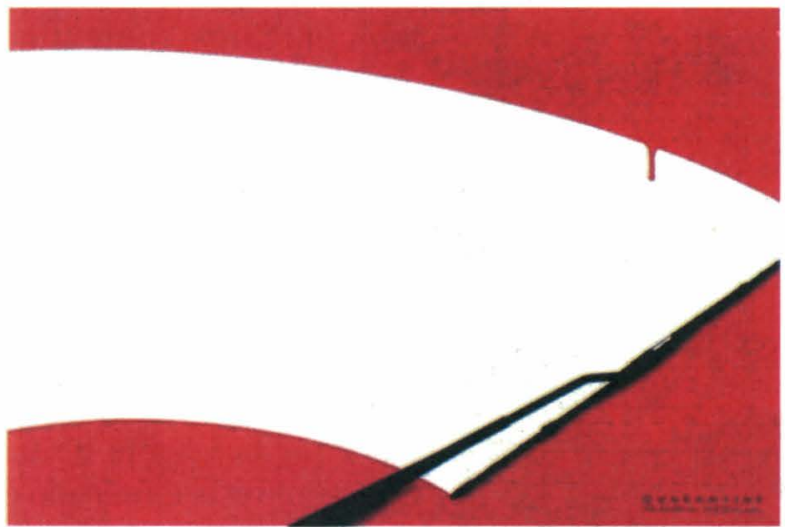

Figura 5. Afiche de una campaña de prevención de accidentes en Miami.

fáctico, sino que responde a una lógica abductiva. Es neçesario encadenar un razonamiento para explicar el baño de sangre en el parabrisas del automóvil. Este tipo de razonamiento parte de un caso particular: la sangre roja que chorrea del parabrisas; luego evoca una regla general en la memoria del lector: "la imprudencia puede provocar accidentes viales con heridas (de allí la sangre)". La conclusión, también particular, es el caso que quiere exponer el mensaje: "Los accidentes de tránsito son altamente peligrosos porque implican pérdida de sangre y riesgo de muerte"'. La figura retórica utilizada es la metonimia, existe una contigüidad existencial entre la sangre y el color rojo (la aparición de un elemento implica la presencia del otro). A otro nivel, también es una metonimia la sustitución del efecto (sangre) por la causa (accidente).

Más allá de las asociaciones metonímicas analizadas, en la propaganda política, los colores son usados con valores simbólicos, con una propuesta de lectura desde un marco ideológico. El cartel ruso de la Figura 6 presenta un fondo rojo, que se ennegrece hacia abajo. La tipografía que hace referencia a la resistencia socialista en Chile en 1977 y la leyenda " Venceremos!" son rojas y contrastan con los sombríos símbolos fascistas (las esvásticas) que sustituyen a las púas del alambrado de los campos de concentración donde eran recluidos los presos políticos. La interpretación de este enunciado requiere mayores 


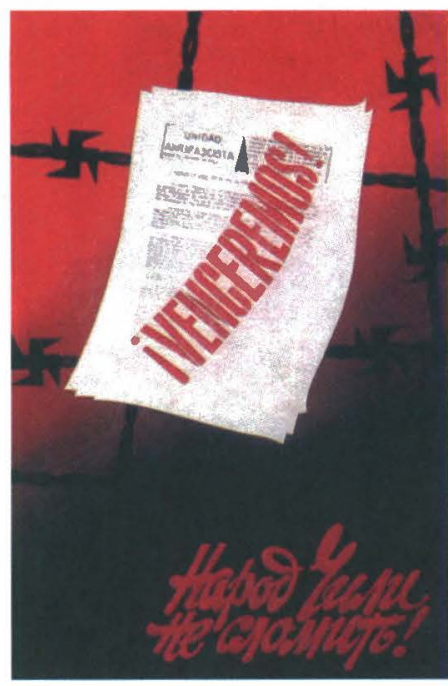

Figura 6. Afiche diseñado por Kazdan, en Rusia, en apoyo a la resistencia chilena, 1977.

conocimientos contextuales y la lectura de una serie deductiva, un tipo de razonamiento más complejo que la mera ejemplificación. La argumentación se articula de modo entimemático y compromete una dinámica temporal. Parte de una premisa general: "El fascismo es negro y significa muerte". La premisa menor predica sobre un particular: "Hoy, Chile está dominado por el negro fascismo"; la conclusión, también particular, es: "Chile está dominado por la muerte". El otro entimema, se relaciona con el futuro y la promesa explícita "Venceremos". La premisa general es: "El socialismo es rojo, es la liberación"; "Chile puede abrazar la ideología socialista". La conclusión es: "Chile puede ser liberado de la dictadura". La figura retórica dominante es la metáfora, ya que los colores por sí sustituyen a las ideologías. A su vez la oposición cromática (antítesis) refuerza este antagonismo.

La siguiente cita describe el uso del color rojo como comunismo en el discurso oficial estadounidense, con connotaciones negativas que provienen de activar la asociación del rojo con el peligro:

La dinastía de los Somoza, que los marines habian puesto en el trono, duró medio siglo, hasta que en 1979 fue barrida por la furia popular. Entonces, el presidente Ronald Reagan montó a caballo y se lanzó a salvar a su país amenazado por la revolución sandinista. Nicaragua, pobre entre los pobres, tenía, en total, cinco ascensores y una escalera mecánica, que no funcionaba. Pero Reagan denunciaba que Nicaragua era un peligro; y mientras él hablaba, la televisión mostraba un mapa de Estados Unidos tiñéndose de rojo desde el sur, para ilustrar la invasión inminente. ¿El presidente 
Bush, le copia los discursos que siembran el pánico? ¿Bush dice Irak donde Reagan decía Nicaragua? (Galeano 2003)

Queda claro que en los últimos dos ejemplos la lectura del símbolo cromático (rojo como socialismo o rojo como comunismo) va a tener una connotación positiva o negativa según quién propone el mensaje y a quién intenta persuadir. Esta situación no es un error, simplemente manifiesta la coexistencia de valores sociales opuestos. Los mensajes basados en alguno de ellos resultarán creíbles y convocantes para el sector de público que previamente adhiera a ese cuerpo ideológico.

\section{Publicidad}

Nuestro tercer género es la publicidad. El rojo (vitalidad, pasión sexual) asociado al negro (noche, sofisticación, misterio) y con toques de blanco son colores usados para persuadir a potenciales consumidores sobre valores o cualidades atribuidas a un producto (Figura 7). El género publicitario comunica valores de marcas y productos de consumo con la intención de persuadir sobre las ventajas de su adquisición a destinatarios definidos como su target.

Según los estudios de márketing, el rojo es considerado "desclasificador", es decir, un color que no contiene marcadores de clase, y por ello es apropiado para marcas de productos de consumo masivo (piénsese en el exitoso rojo Coca Cola). Al rojo también se le atribuye promover la pérdida de la noción del tiempo, por eso es el color elegido (con accesorios negros y

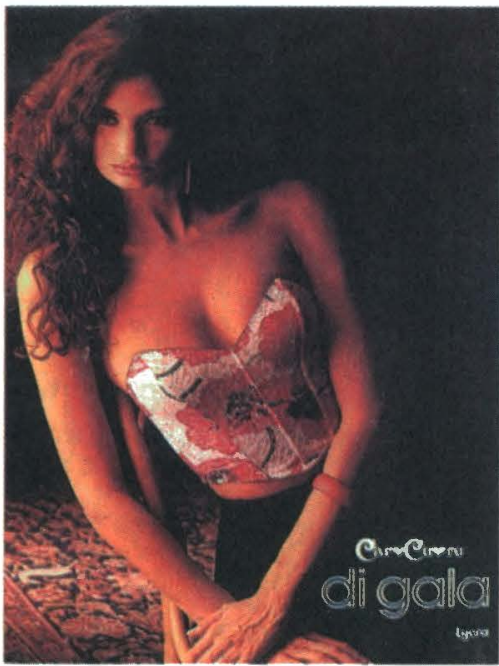

Figura 7. Publicidad de ropa interior de mujer. 


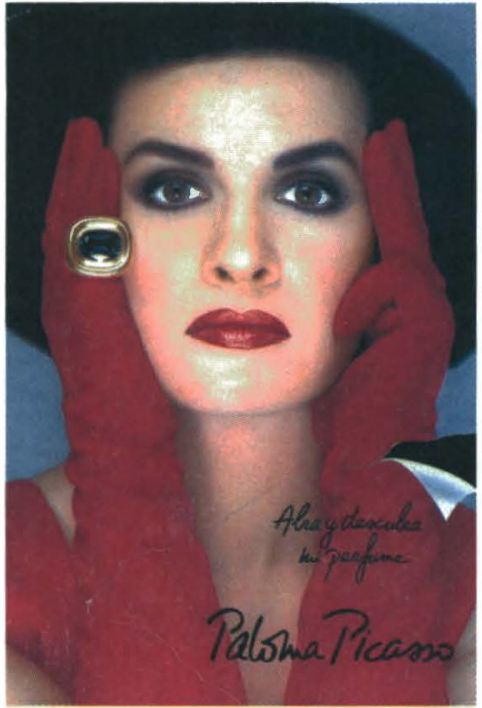

Figura 8. Publicidad de perfume.

blancos) para locales comerciales como casinos, bares, discotecas y entretenimientos. También es notable su uso para destacar lo sabroso y apetitoso en el rubro gastronómico (en packaging, publicidad, marcas y arquitectura corporativa).

La publicidad del perfume Paloma Picasso exorcisa los fantasmas sobre el uso de esta tríada cromática y exalta sus resonancias positivas (Figura 8). Persuade con una argumentación inductiva, la imagen en sí misma. Parte de un particular: Paloma Picasso vestida de rojo, con labios también muy rojos que contrastan con la piel blanca. El pálido rostro está enmarcado por negros cabellos, ojos y guantes negros. Esta imagen se atribuye los valores de seducción, pasión, esteticismo y españolidad, que podría ser emulada por cualquier mujer que consuma la fragancia publicitada. Si hay identificación con la imago propuesta (tipo físico de mujer y valores que encarna), también la habrá con los colores y el producto; será eficaz el mensaje para ese sector de consumidores. La figura retórica que predomina es la repetición o aliteración cromática, que acentúa los rasgos connotativos mencionados. Toda la imagen funciona de manera metafórica; el rostro sustituye el frasco de perfume, con el que guarda similitudes morfológicas y cromáticas.

\section{Conclusión}

¿Hay paradojas en la argumentación cromática? Lo bueno o lo malo. La vida y la muerte. El peligro o la vitalidad. La alegría o la depresión. Lo claro o lo enigmático. La seducción o el veneno. El 
sexo o la muerte. A través de los ejemplos analizados, el contexto, el género persuasivo del que se trate, quien propone el mensaje y quién fuese el destinatario permitían clarificar estas potenciales ambigüedades. Esto podría hacer suponer que el uso de esta tríada no garantiza un significado unívoco, aunque sí hay sentidos codificados en relación con los contextos.

Sin embargo, podría formularse como hipótesis que las connotaciones más primarias (rojo como sangre y alerta; negro como noche y muerte) aunque puedan revertirse y cambiar de signo negativo a positivo, permanecen siempre subyacentes. El uso de estos colores en imágenes del diablo o del vampiro Drácula no es tan distante de los alegres payasos, el bueno de Papá Noel y los sagrados sacerciotes. No se trata de una utilización arbitraria del color, sino más bien de la apropiación de los atributos negativos del otro para absorberlos, neutralizarlos y exorcisarlos. Aunque estas figuras se sepan benefactoras, conservan su ambivalencia. No en vano su presencia atemoriza a los niños.

\section{Bibliografia}

ARISTÓTELES. 350 a.C. Retórica. Hay una versión inglesa, Rhetoric, disponible en Internet, http:/classics.mit.edu/ Aristotle/ thetoric.html.

BERLIN, B. y KAY, P. 1969. Basic color terms. Berkeley, CA: University of California Press.

GAGE, J. 1993. Color and culture. Boston: Little, Brown, and Co.

GALEANO, E. 2003. Artículo publicado en Página 12 (Buenos Aires), marzo.

HUTCHNGS, J. 1989. "Colour in folklore, superstition, tradition, and legend", en AIC Color 89. Proceedings of the 6th Congress. Buenos Aires: Grupo Argentino del Color, vol. II, 54.

1993 "International survey on colour in folklore, belief and tradition -a progress report", en AIC Color 93, Proceedings of the 7th Congress. Budapest: Hungarian National Color Committee, vol. C, 153-157. 
1997. "Japan and Britain -A comparative colour folklore", en AIC Color 97, Proceedings of the 8th Congress. Kioto: The Color Science Association of Japan, vol. II, 775-778.

KWON, Y. G. 2002. "The signs and symbols of red color in East Asian countries", en AIC Color 2002, Proceedings of the Interim Meeting. Maribor, Eslovenia: Slovenian Colorists Association, 291-295.

LÓPEZ PASQUALI, L. 1998. Fascinación y origen de las preferencias. Buenos Aires: Editorial Peñafield.

PEIRCE, C. S. 1860-1908. 1931-1935. The collected papers. Cambridge, MA: Harvard University Press. 